\title{
Arte, cultura e conhecimento escolar: a integração é possível!
}

\author{
Adriana Lia Friszman de Laplane \\ Dayane Gonçalves** \\ Tatiana Brochado Portela
}

\section{Resumo}

Uma pequena equipe de pesquisa de uma universidade e duas professoras de uma escola estadual de ensino fundamental situada em uma cidade do estado de São Paulo criaram, no contexto de um projeto de pesquisa apoiado por um órgão de financiamento estadual, uma proposta de trabalho que integra várias áreas de conhecimento, incluindo a Arte no trabalho com projetos sobre um tema comum. A proposta se baseou na ideia de que a apropriação da cultura depende de um conjunto de ações, conhecimentos e saberes que podem ser mobilizados para compreender a realidade e agir sobre ela. A partir da escolha inicial de um eixo temático (a memória), as professoras planejaram diferentes atividades que promoveram o engajamento dos alunos e envolveram uma variedade de conhecimentos e de ações de pesquisa, ensino e aprendizagem. O presente estudo reflete sobre as implicações do trabalho com projetos que propõem a integração de disciplinas e áreas de conhecimento em sala de aula e sobre seu potencial para mudar as concepções e práticas tendentes à fragmentação e para ampliar e enriquecer a cultura de todos os participantes.

Palavras-chave: Cultura. Projetos. Interdisciplinaridade. Escola. Ensino-aprendizagem.

\section{Introdução}

Uma das tarefas principais da escola é apresentar, ensinar e promover o domínio da linguagem escrita. A escrita é a ferramenta que permite o acesso a vários tipos de conhecimento, ideias, pensamentos e reflexões que podem ter sido formulados em tempos muito distantes do presente. A escrita se adquire de forma diferente da linguagem falada (VIGOTSKY, 1991). Basta que a criança conviva com pessoas falantes

\author{
Recebido: 30/11/2015 - Aprovado: 17/02/2016 \\ http://dx.doi.org/10.5335/rep.v23i1.6356
}

\footnotetext{
Doutora em Educação pela Universidade Estadual de Campinas. Professora do Departamento de Desenvolvimento Humano e Reabilitação da Faculdade de Ciências Médicas da Universidade Estadual de Campinas. E-mail: adrifri@fcm. unicamp.br

** Professora do Ensino Fundamental, Secretaria de Educação do Estado de São Paulo. E-mail: dayyane.g@gmail.com

*** Professora de Artes, Secretaria de Educação do Estado de São Paulo. E-mail: portela13@gmail.com
} 
de uma língua para que no início do segundo ano de vida, na maioria dos casos, ela comece a falar palavras isoladas e, depois, frases de duas e três palavras, de maneira que o vocabulário e a compreensão sobre o funcionamento da língua se ampliam, gerando recursos expressivos cada vez mais complexos e eficazes para a comunicação.

Viver em uma sociedade letrada não garante, entretanto, a aquisição da escrita. Objeto cultural, criado e aperfeiçoado na interação social a partir da linguagem, a escrita é uma sofisticada ferramenta cuja aprendizagem depende da instrução (VIGOTSKY, 1991), e é afetada por fatores de diferentes ordens. Entre eles, as condições socioculturais da comunidade de origem do aprendiz e a coincidência ou não entre os valores da comunidade, da família e da escola são responsáveis pelo sucesso ou fracasso acadêmico e por grande parte das dificuldades que muitas crianças enfrentam no início da vida escolar.

A desigualdade e as diferenças socioeconômicas e culturais que dividem os alunos em grupos mais ou menos próximos da linguagem, da cultura e das práticas escolares (BOURDIEU, 1998, 2004) ajudam a compreender o problema sempre atual do grande número de crianças e adolescentes que, malgrado as políticas, projetos e programas formulados por governos e especialistas, apresentam baixo (ou mesmo insuficiente) desempenho nas tarefas que requerem o uso da leitura e da escrita.

Os estudos sobre letramento (KLEIMAN, 1995; ROJO, 1998; STREET, 2003, 2006; SOARES, 2004) abordam a importância do sentido e do significado social das práticas que envolvem a escrita e contribuem para a compreensão dos fatores de ordem cultural que atravessam e condicionam a aprendizagem. Entende-se, assim, que alguns dos alunos provenientes de lares ou comunidades em que a leitura e a escrita são pouco utilizadas não tenham, inicialmente, interesse em dominar essas práticas.

O domínio da leitura e da escrita requer um investimento emocional sustentado, já que o processo de aquisição é demorado e envolve a compreensão dos aspectos linguísticos da escrita (gramaticais, semânticos, pragmáticos e fonológicos). A motivação é, portanto, um fator importante a ser considerado. Mas a motivação é fortemente influenciada pelo ambiente cultural, o que desloca o foco da atenção para o contexto de vida do aprendiz, para os usos sociais da escrita nesse contexto, para as tradições familiares e das comunidades que pertença, para os modelos de uso com os quais crianças de diferentes meios socioeconômicos e culturais convivem e para os modos de ensinar, que devem ser sensíveis o suficiente para incorporar esse conjunto de fatores.

Por sua vez, a escola, instituição encarregada de difundir o conhecimento, se organiza há muito tempo de forma disciplinar, e, mesmo em tempos de interdisciplinaridade, essa divisão se instala já nos primeiros anos do ensino fundamental. A educação assim organizada se caracteriza pela compartimentalização e fragmentação 
do conhecimento e pela primazia de materiais altamente estruturados, que usam e abusam de atividades com respostas únicas, que raramente promovem a tomada de decisões, a flexibilidade e a integração de conhecimentos provenientes de diferentes campos. Essas características do ensino tradicional não colaboram para despertar e suscitar o interesse e a curiosidade necessários para motivar os alunos a aprender, o que acaba tornando a vida escolar um jogo de poder e resistência: os professores ensinam conteúdos e dão tarefas e exercícios que os alunos não realizam ou realizam de forma mecânica, sem se apropriar do conhecimento. $\mathrm{O}$ resultado, do ponto de vista da aprendizagem significativa e situada, útil para a vida, é frustrante para todos.

Tendo como pano de fundo essas questões, o presente estudo tem por objetivo discutir possibilidades de ensino que privilegiam uma concepção ampla e multifacetada dos processos envolvidos nos atos de ensinar e aprender. A discussão é fruto de uma experiência de pesquisa e intervenção em uma escola pública de uma cidade do interior do estado de São Paulo e contempla os aspectos observados pela equipe de pesquisa (professoras da escola e equipe da universidade) durante o desenvolvimento do projeto.

\section{Pesquisa e intervenção na escola}

Durante três anos, a equipe de pesquisa de uma universidade, composta por uma docente e uma assistente de pesquisa, participou de reuniões e atividades escolares no contexto do projeto Inclusão escolar: das políticas públicas às práticas pedagógicas. ${ }^{1}$ A pesquisa investigou as práticas escolares e ajudou, como forma de contribuir para a melhoria do ensino, a formular atividades que promovessem 0 uso da escrita, área identificada pelas professoras da escola como a menos desenvolvida pelas crianças. Entre as atividades propostas estava a realização de uma feira onde seriam apresentados os diferentes projetos desenvolvidos pelas turmas do $1^{\circ}$ ao $5^{\mathrm{o}}$ ano do ensino fundamental ao longo do ano. Cada professora escolheu um tema (de comum acordo com a sua turma) e um modo de trabalho, e uma parte das atividades da semana era destinada a avançar na realização dos mais diversos projetos: coleção de objetos antigos, recopilação de brincadeiras tradicionais, mitos, lendas e histórias de Campinas e das cidades, estados e regiões de onde as famílias dos alunos são provenientes, estudo sobre o bairro, entre outras atividades.

O trabalho foi desenvolvido por cada professora de sala e contou com o apoio da professora de Artes, que colaborou com todas as turmas. Entre esses projetos, o da turma do $3^{\circ}$ ano, o projeto "Minha escola, meu bairro", será tomado como exemplo e base das presentes reflexões (GONÇALVES, 2010; LAPLANE, 2013; PORTELA, 2010). 


\section{0 trabalho com projetos: arte, letramento e memória}

O trabalho com projetos é uma prática conhecida pelos professores do ensino fundamental. Entretanto, ela é, em geral, pouco utilizada. A literatura sobre o assunto aponta as vantagens da modalidade, que parte do princípio de que o conhecimento se articula em um processo dinâmico e não linear que não requer uma ordem rígida para seu desenvolvimento, e por isso é possível organizar atividades e articular conhecimentos muito diversos por meio das mais variadas atividades (HERNANDEZ; VENTURA, 1998).

Essa metodologia de trabalho permite ao grupo estabelecer metas, planejar procedimentos para atingi-las e programar as ações intermediárias, envolvendo no processo informações e conhecimentos que se apresentam sempre como necessários ou funcionais às metas. $\mathrm{O}$ uso de projetos em sala de aula também proporciona a oportunidade de distribuir a responsabilidade da execução das tarefas planejadas entre os membros do grupo e de diversificar as ações de modo a valorizar seus diferentes recursos, habilidades e conhecimentos. Alunos com diferentes características e estilos podem ser valorizados em diferentes momentos do projeto, e isso pode ajudar a criar um clima de cooperação e união do grupo. Os laços de amizade podem se estreitar durante o trabalho compartilhado e a variedade de ações, temas e procedimentos poderá ter $\mathrm{o}$ efeito de incentivar o interesse e a persistência na realização das tarefas. Esse tipo de trabalho costuma também ter efeito benéfico na autoestima dos alunos.

Por que, então, o trabalho com projetos não é mais difundido como prática de ensino e aprendizagem capaz de ampliar e integrar conhecimentos de diferentes áreas? As razões são várias. Uma delas é que a própria formação de professores é marcadamente disciplinar, além de simplificada, com poucas oportunidades para a integração do conhecimento e das práticas. Outros motivos para o desestímulo ao trabalho com projetos residem nas concepções que subjazem à formação em serviço e aos projetos e programas destinados à melhoria do ensino. A maioria desses programas utiliza materiais que apresentam sequências fixas de temas e atividades.

Essa dinâmica de formação tem sido criticada por destituir os professores de autoridade e independência para conduzir o processo pedagógico, impedir a adequação das atividades de sala de aula às necessidades dos alunos e por inscrever-se na lógica da mercantilização da educação (MAGALHÃES; AZEVEDO, 2015; CORRÊA e CASTRO; AMORIM, 2015). Nesse sentido, mesmo que se considere a difusão de ideias sobre a formação de um professor reflexivo, ativo na construção de um saber gerado nas práticas de ensino (TARDIF, 2013), as próprias políticas e programas de melhoria do ensino, com seu caráter prescritivo, além dos modos de implementação impostos pelos gestores, que, às vezes, engessam ainda mais as possibilidades de ação dos professores, constituem travas que obstaculizam essa prática docente. 
Por fim, observa-se que a modalidade de trabalho por projetos requer para seu sucesso um investimento considerável em pesquisa, estudo e planejamento, e essas ações dependem também do apoio logístico e do incentivo da gestão da escola. De outro modo, as condições para a implementação de projetos mais ambiciosos não se materializam e os projetos não podem assumir a dimensão e a profundidade que os proponentes geralmente almejam.

Um dos pontos de partida do projeto sobre o qual refletiremos aqui foi o compromisso das professoras com a meta de despertar o interesse e a curiosidade dos alunos bem como de promover o seu engajamento nas atividades. As professoras queriam que os alunos pensassem, refletissem e conversassem sobre os temas relacionados ao projeto (MOTA, 2002). Para isso, elas criaram oportunidades, situações e momentos em que a classe devia tomar decisões, fazer escolhas, planejar, argumentar e negociar temas, atividades e prioridades. O próprio nome do projeto foi escolhido pela turma. Também foi elaborado um roteiro de trabalho que previa a realização de diferentes tipos de atividades.

As práticas de letramento (SOARES, 2004) se fizeram presentes durante todo o processo. As questões formuladas e as atividades propostas para respondê-las requisitaram o domínio de diferentes gêneros textuais e discursivos. Os alunos realizaram pesquisas na internet, em livros e enciclopédias; fizeram anotações de campo e resumiram informações de diferentes fontes; entrevistaram familiares e visitantes; escreveram legendas para as obras criadas e expostas na mostra de final de ano; elaboraram textos informativos e explicativos sobre os tópicos que lhes interessava comunicar; digitaram, corrigiram e editaram seus textos e explicaram oralmente as diferentes etapas do projeto e os processos de produção dos materiais expostos. A escrita foi utilizada como ferramenta e seu uso aprimorado e diversificado de acordo com a exigência de cada atividade.

A arte foi integrada ao projeto de forma natural. Atividade fundamental do ser humano, a arte produz objetos capazes de suscitar sentimentos e emoções no receptor e permite sempre novas leituras e novos sentidos (BOSI, 1986). Aliando razão, emoção, percepção e sensibilidade, a atividade artística promove a expressão do universo simbólico dos alunos, a aprendizagem e o desenvolvimento (ARSLAN; IAVELBERG, 2006). As ideias de que a leitura de imagens também prepara para outras leituras (BARBOSA, 1995) e promove um envolvimento pessoal particular que interpela o sujeito e permite estabelecer relações com outras áreas de conhecimento (PILLAR, 2004) também se coadunam com a noção ampla de letramento aqui assumida, que considera a atividade simbólica humana como capaz de promover um encontro entre as dimensões subjetivas, emocionais e intelectuais e as contextuais e culturais em que ocorre. Essa concepção recebe também a inspiração do educador Paulo Freire, que diz: "[...] a compreensão do texto a ser alcançada por sua leitura crítica implica a percepção das relações entre o texto e o contexto" (1995, p. 8). 
O trabalho empreendido baseou-se nessas premissas para articular ações e conhecimentos e desdobrar atividades que foram surgindo das discussões e da contribuição da turma e das professoras (GONÇALVES, 2011; PORTELA, 2011).

\section{Vista aérea do bairro}

A primeira ação do projeto foi um exercício de memória integrado a uma atividade artística: os alunos precisaram delimitar um espaço do bairro de que gostassem e representar através do desenho a vista aérea daquele espaço. Essa atividade integrou uma técnica de representação gráfica e um trabalho discursivo. Do ponto de vista artístico da arte, foi desenvolvida uma possibilidade de representação simbólica cujo elemento central foi o espaço e a perspectiva do observador. A atividade envolveu um trabalho sistemático de leitura da imagem e produção criativa que se tornaram marcas do projeto.

Figura 1 - Desenhos produzidos por aluno com papel Canson $(30 \times 40 \mathrm{~cm})$ e giz de cera
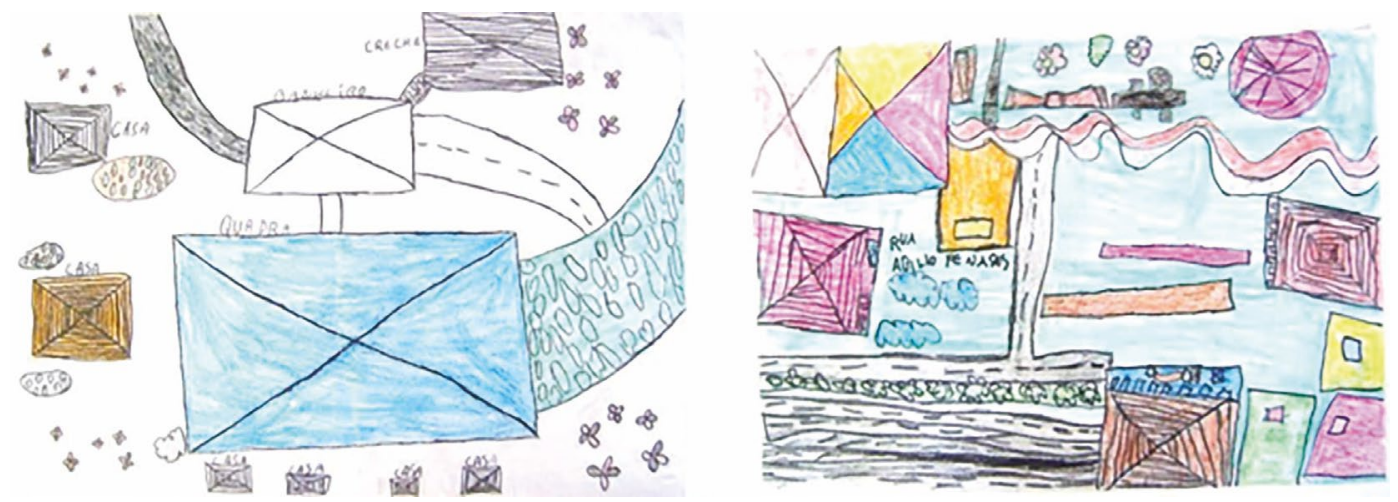

Fonte: elaboração das autoras.

\section{Saída de campo}

A segunda ação do projeto foi uma saída de campo pelo bairro, na qual foi realizado o registro fotográfico daquilo que chamava a atenção dos alunos. Esses, munidos de um caderninho, registraram por meio da escrita os detalhes e as condições em que se encontravam os diferentes locais percorridos.

Inicialmente, a maioria das ideias era sugerida pelas professoras, mas, poucas semanas depois, os próprios alunos começaram a apresentar ideias e propostas de atividades. Essa mudança foi identificada como um sinal de engajamento e apro- 
priação do projeto pelos alunos. A partir do registro de campo, foram produzidas, em sala, maquetes de locais selecionados do bairro. Além disso, os aspectos observados na saída de campo constituíram o material para compor um conjunto de textos que os alunos digitaram nos computadores da sala de informática da escola.

Atrelados a essas atividades, foram incluídos os conceitos procedimentais necessários para sistematizar o trabalho de construção e confecção das maquetes, e, ainda, a todo o momento foram retomados os aspectos relacionados ao trabalho coletivo, à troca entre colegas e à necessária negociação entre os alunos e as professoras, para tomar as decisões e fazer as escolhas respeitando a opinião de cada participante.

Os conteúdos conceituais também foram explorados. O estudo dos conceitos de bairro residencial, industrial e comercial e a análise dos conceitos de ambiente urbano e rural contribuíram para a discussão do processo de transformações que ocorreu nos espaços ao longo do tempo. Durante o estudo das características atuais do bairro, surgiu a curiosidade de saber se os locais analisados sempre tiveram as características observadas. Para responder às dúvidas, a avó de um aluno da escola aceitou o convite e preparou uma palestra para os alunos, mostrou fotos antigas de vários locais visitados na saída de campo e contou muitas histórias que revelaram algumas particularidades do modo de vida das pessoas no passado.

Após a palestra proferida pela moradora do bairro e a saída de campo, ficou constatado o problema do lixo e da deficiente conservação de equipamentos, prédios comunitários e praças do bairro.

Figura 2 - Saída de campo pelo bairro da escola
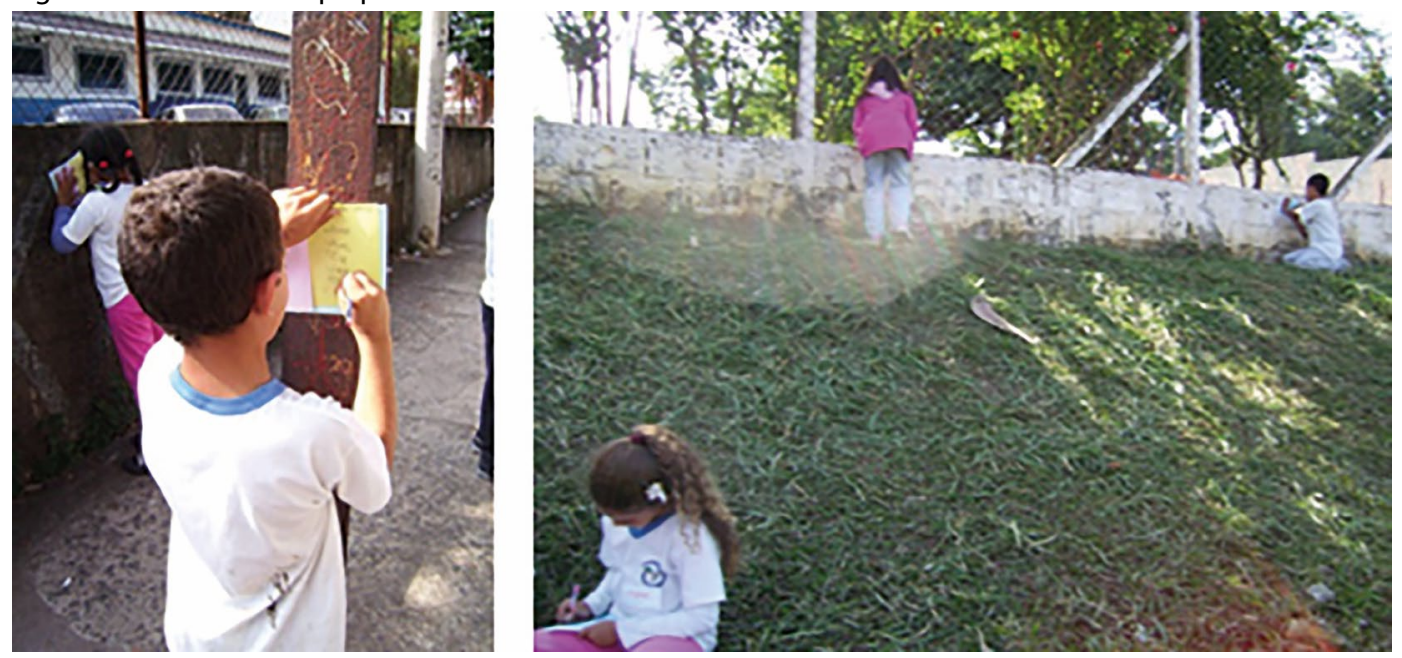

Fonte: elaboração das autoras. 
Figura 3 - Maquetes dos espaços do bairro produzidas pelos alunos
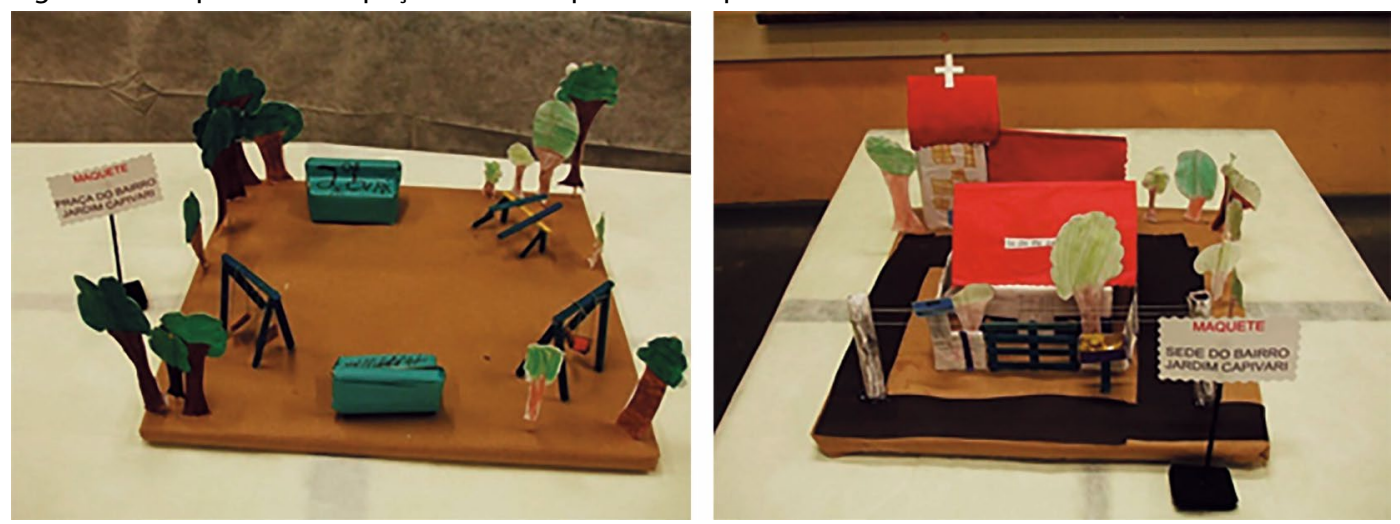

Fonte: elaboração das autoras.

\section{Saída de campo (2)}

Outra saída de campo foi planejada com o objetivo de recolher o lixo das ruas. Essa atividade foi intitulada "passeata de limpeza". A atividade foi divulgada aos familiares e membros da comunidade, e algumas mães de alunos participaram. Os alunos estavam indignados com a falta de limpeza do bairro, e durante a discussão posterior surgiram questões como: Será que a única solução que existe para resolver a situação do bairro é fazer passeatas de limpeza? Só este tipo de atividade resolverá o problema do lixo? Quem são os responsáveis por esta situação? Que outras ações poderiam ser desenvolvidas para lidar com os problemas do bairro?

Figura 4 - Saída de campo (2)
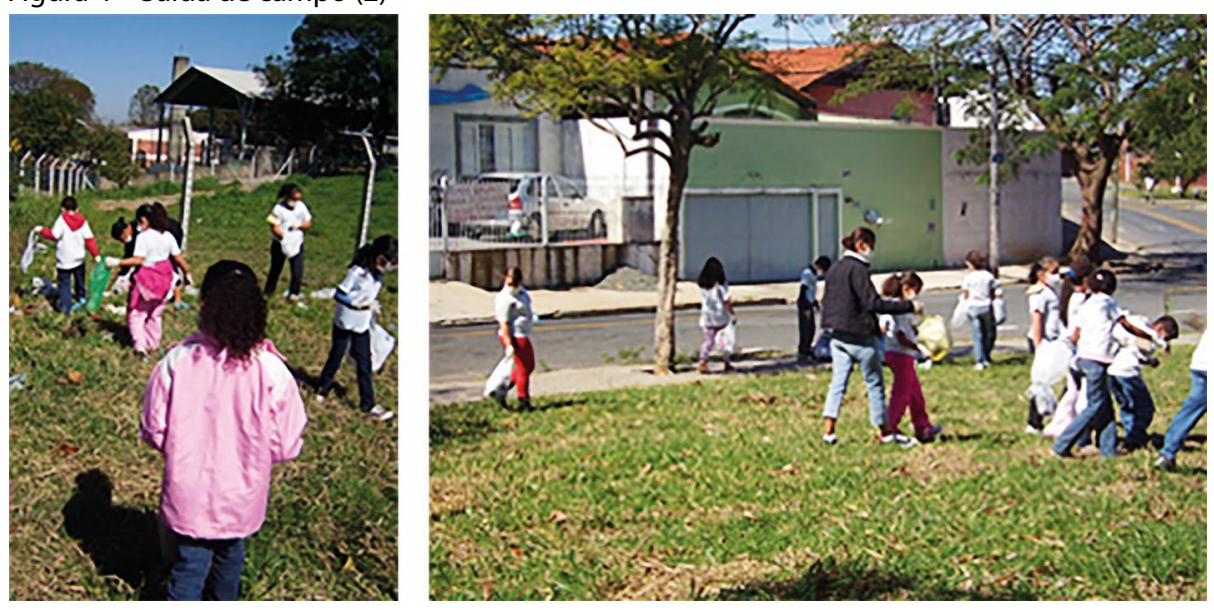

Fonte: elaboração das autoras. 
Figura 5 - Lixo recolhido na saída de campo (2)

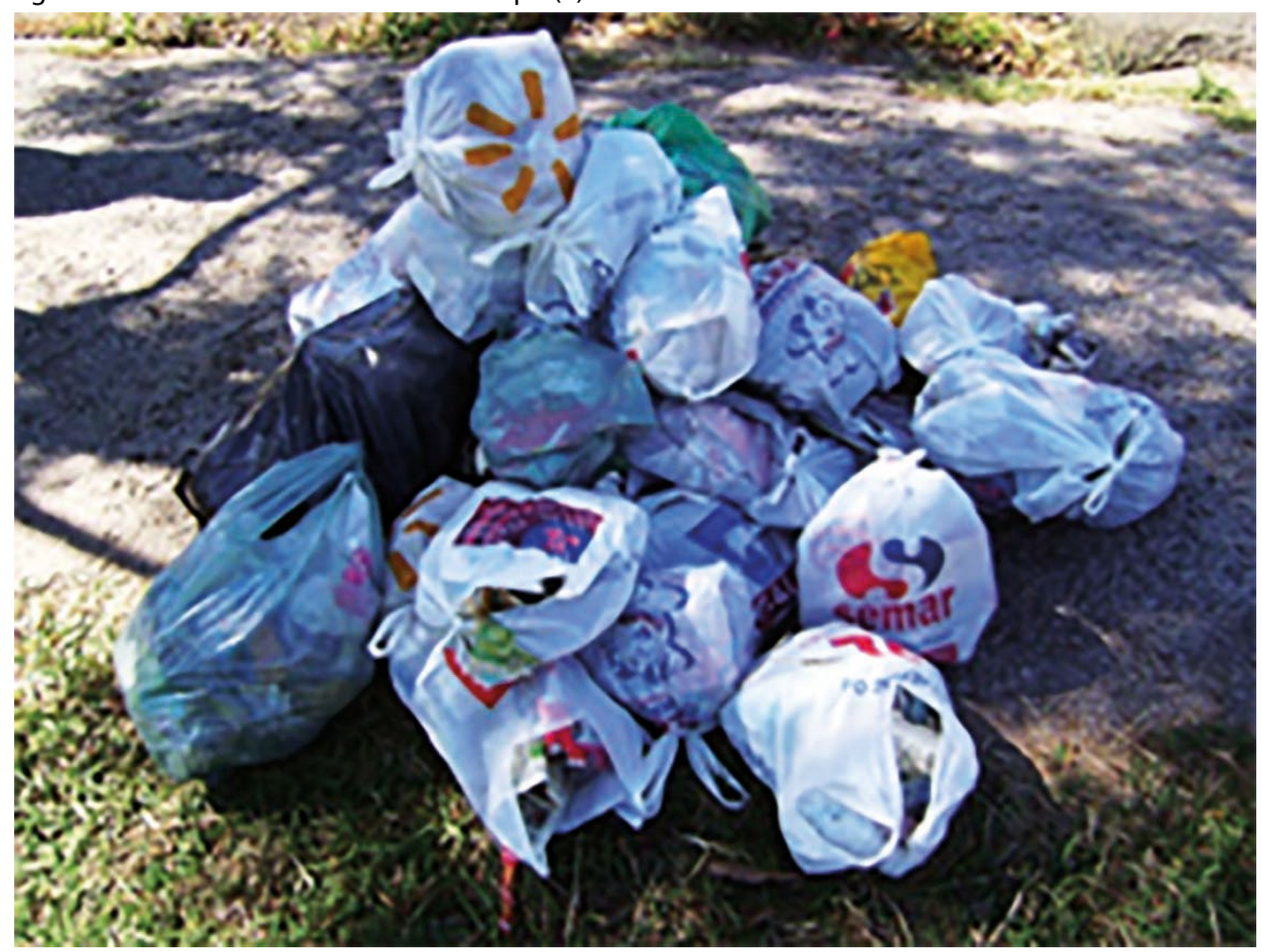

Fonte: elaboração das autoras.

\section{Arte e lixo}

Entre as propostas para dar continuidade ao trabalho surgiu a ideia de utilizar o lixo encontrado nas ruas (que foi recolhido e ensacado) para construir uma obra de arte e expô-la à comunidade. Na perspectiva da conservação do patrimônio histórico e da discussão sobre a questão ambiental, foram estudados os artistas brasileiros Vik Muniz e Nuno Ramos, que em seus processos de criação utilizam materiais não convencionais na construção poética das suas obras e refletem sobre o uso desses materiais, o acúmulo de objetos, a criação e a memória.

$\mathrm{Na}$ semana seguinte, os alunos começaram a separar e limpar os materiais recolhidos. Organizados em grupos, escolheram, separaram e observaram cada material. Nesse processo, o objeto começa a perder a força e a funcionalidade, e enquanto o valor utilitário e comercial se dilui, inicia-se a observação da materialidade em si, da forma, da cor, da densidade; características fundamentais e inerentes ao objeto artístico que vai emergindo. 
O lixo coletado foi separado, classificado, higienizado e organizado de acordo com as possibilidades de ser aproveitado no trabalho artístico. A ideia era planejar uma pintura cujo corpo inicial fosse composto pelos materiais recicláveis recolhidos.

A seguir, cada grupo colou os materiais (de diferentes tamanhos e formas) na placa. A superfície foi toda preenchida com o material criando tridimensionalidade. Para finalizar, as obras foram pintadas com tinta acrílica. Uma vez concluído o trabalho, que consumiu várias semanas de aula, a classe discutiu o processo de criação e cada grupo, observando sua obra, produziu um texto reflexivo que seria colocado (por solicitação dos alunos) junto à obra na exposição do final do ano.

O trabalho realizado se desdobrou em questionamentos sobre como é o município em que o bairro se localiza.

Figura 6 - Separação do lixo coletado na saída de campo (2)

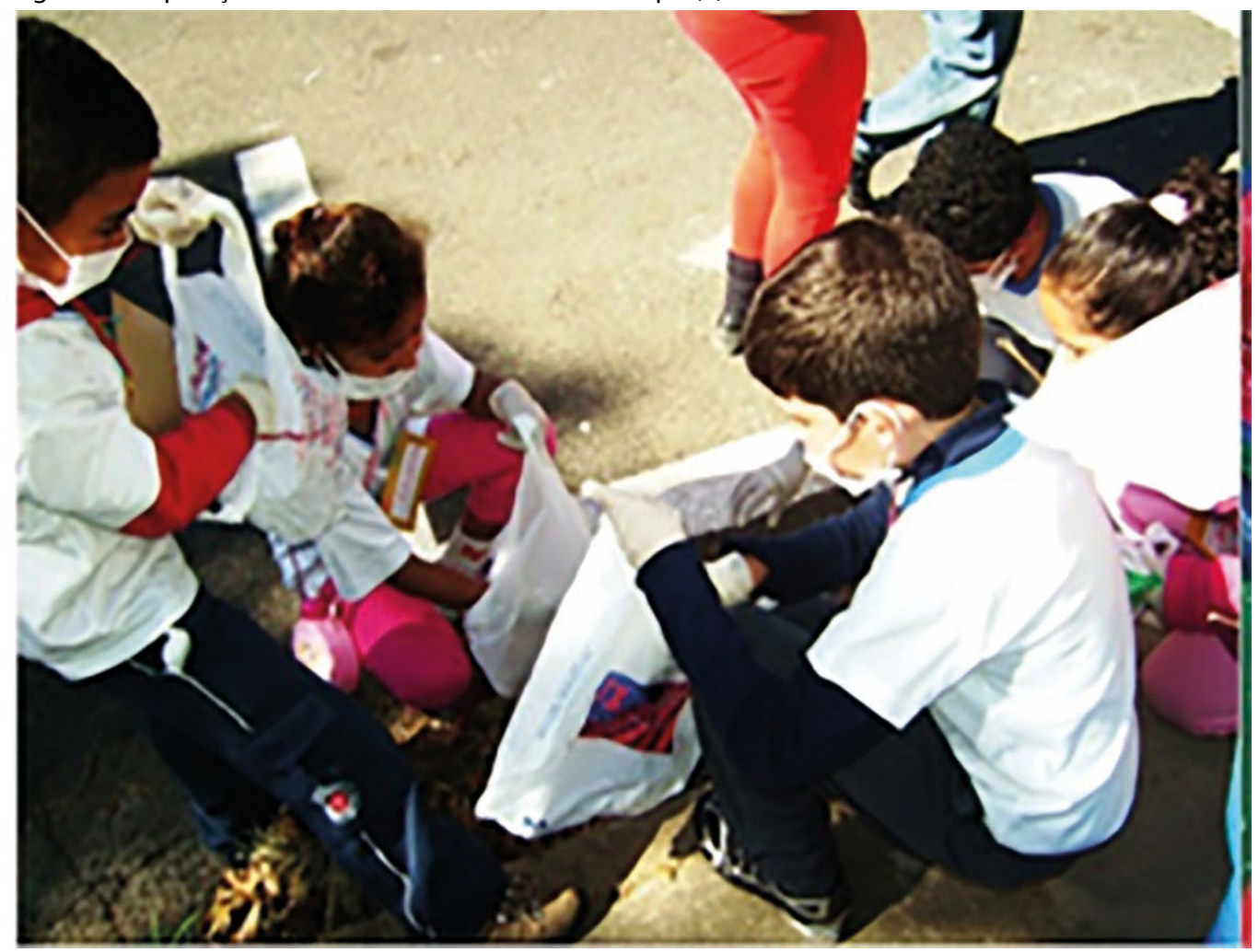

Fonte: elaboração das autoras. 
Figura 7 - Produção da obra: seleção de materiais

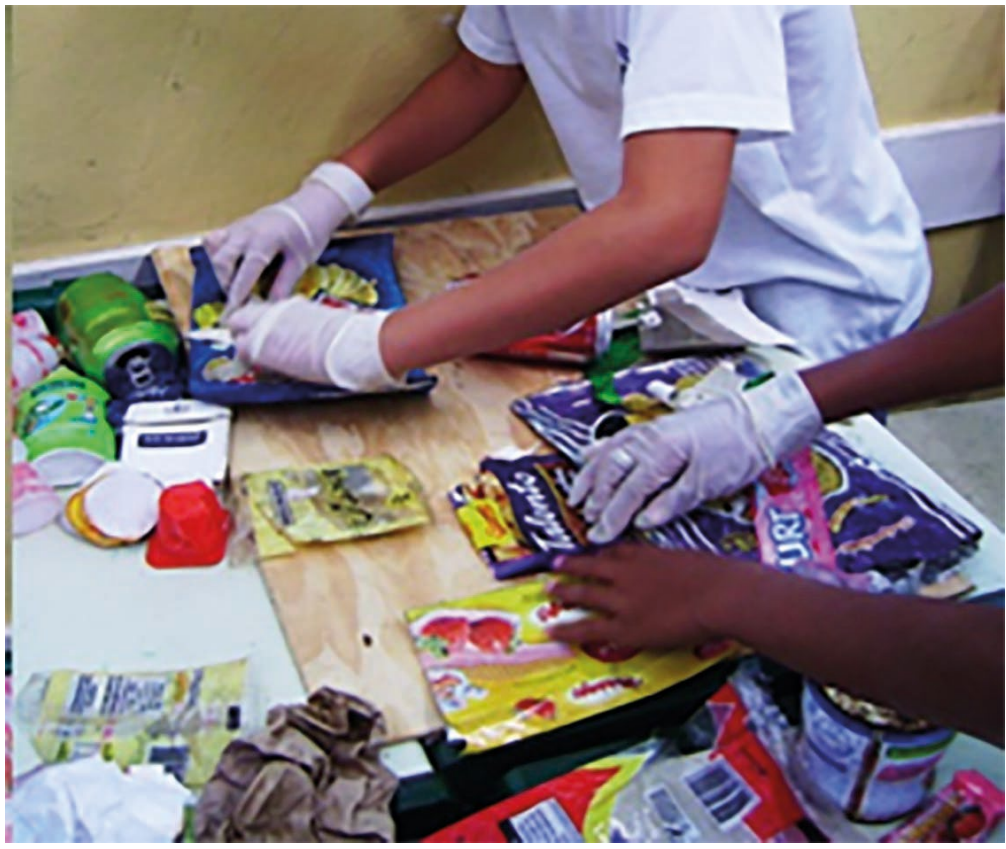

Fonte: elaboração das autoras.

Figura 8 - Produção da obra: colagem dos materiais

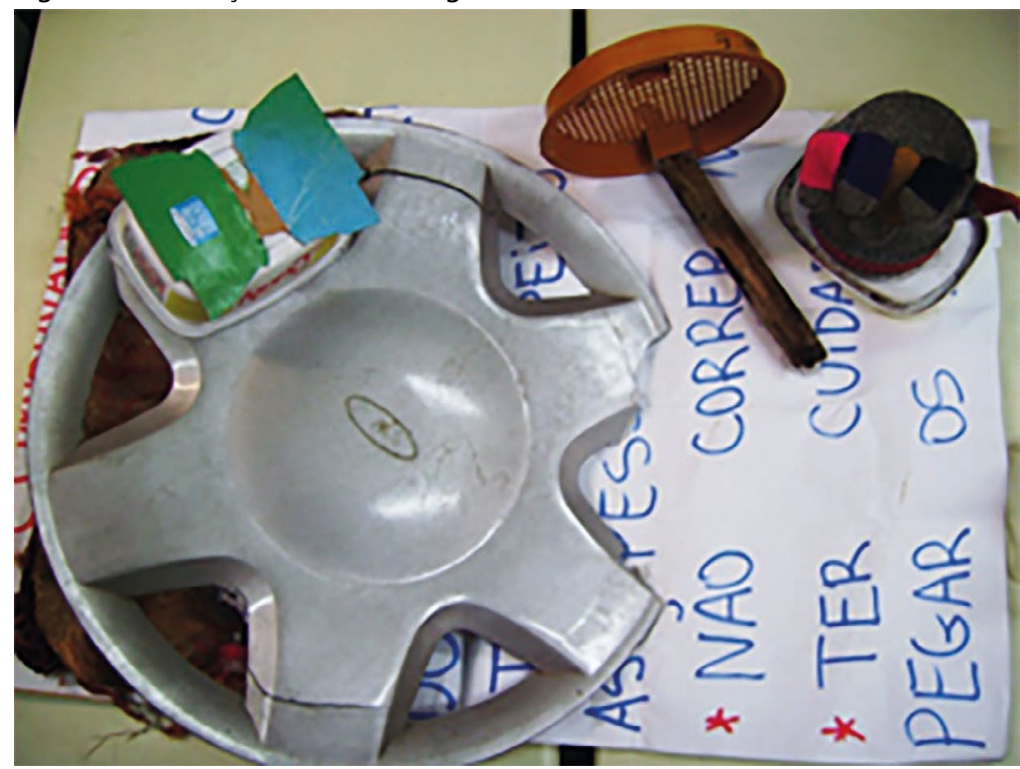

Fonte: elaboração das autoras. 


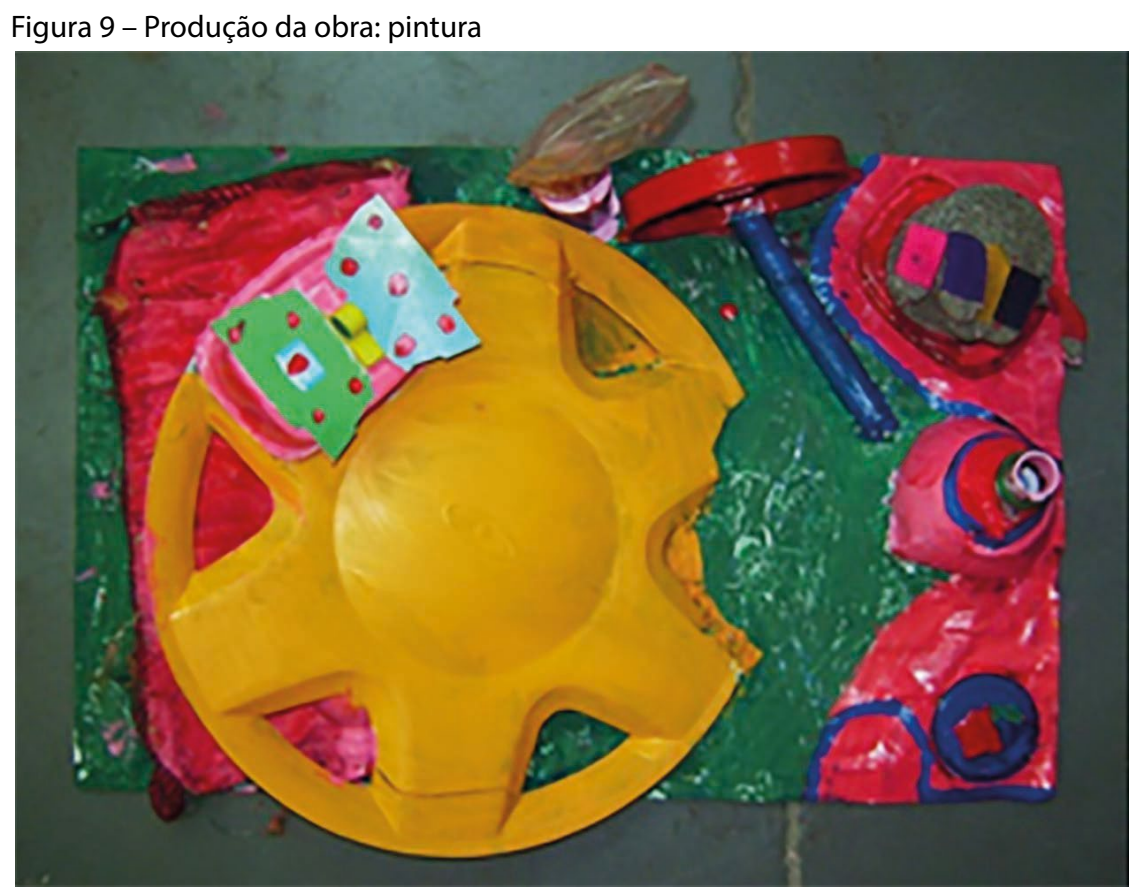

Fonte: elaboração das autoras.

\section{Outras atividades: saída de campo (3) e visita ao Instituto Estre e documentário}

Uma terceira saída de campo foi planejada e realizada para conhecer a cidade e os seus principais pontos de interesse. Um historiador acompanhou a saída e contou a história da cidade, explicou as características dos diferentes monumentos e contou a história dos pontos turísticos. A partir do estudo desses monumentos, foram produzidas miniaturas em papel machê e novas leituras enriqueceram o conhecimento histórico dos alunos sobre a cidade. Ainda, as questões ambientais e de preservação voltaram à tona e foi estudado o conceito de lixo por meio do documentário Ilha das Flores.

A visita ao Instituto Estre, localizado em uma cidade vizinha, realimentou os debates ao fornecer materiais escritos sobre o lixo, apresentar aspectos interessantes do ciclo do lixo e das possibilidades de reciclagem. A visita incluiu a participação em oficinas pedagógicas sobre a geração e o destino do lixo e uma visita ao aterro sanitário. Depois da visita, a turma se debruçou sobre a realização de um documentário em formato de vídeo sobre o lixo do bairro. Os alunos se organizaram em equipes de trabalho, responsáveis por estudar os diferentes aspectos do tema e preparar os textos que serviriam de base para as apresentações. O material es- 
crito foi elaborado pelas equipes e cada aluno leu seu texto durante a gravação do documentário.

\section{Mostra de arte e cultura}

No final do semestre foi organizada uma exposição. Além de expor todos os trabalhos confeccionados ao longo do ano (maquetes dos prédios visitados, fotografias com as suas respectivas legendas, desenhos e pinturas sobre "a vista aérea do bairro", objetos, pequenas esculturas em cerâmica e papel machê e textos variados), os alunos se prepararam para explicar os processos de produção de cada obra exposta e para contar o que sabiam sobre lixo, reciclagem, cidadania, história da cidade, dos seus monumentos e do bairro. Também exibiram o documentário e entregaram folhetos informativos, que eles próprios escreveram, à comunidade.

A mostra, realizada em um sábado pela manhã para permitir o comparecimento de mães e pais trabalhadores, foi bem sucedida. As famílias, ansiosas por conhecer o resultado de um trabalho que tomara todo o semestre, circulavam pelas salas enquanto as crianças explicavam e apresentavam, orgulhosas, as suas obras (maquetes, fotografias, objetos, histórias, desenhos). As professoras organizavam os trabalhos e acolhiam as famílias, oferecendo explicações complementares sobre os materiais expostos, sobre a participação e o desempenho dos alunos.
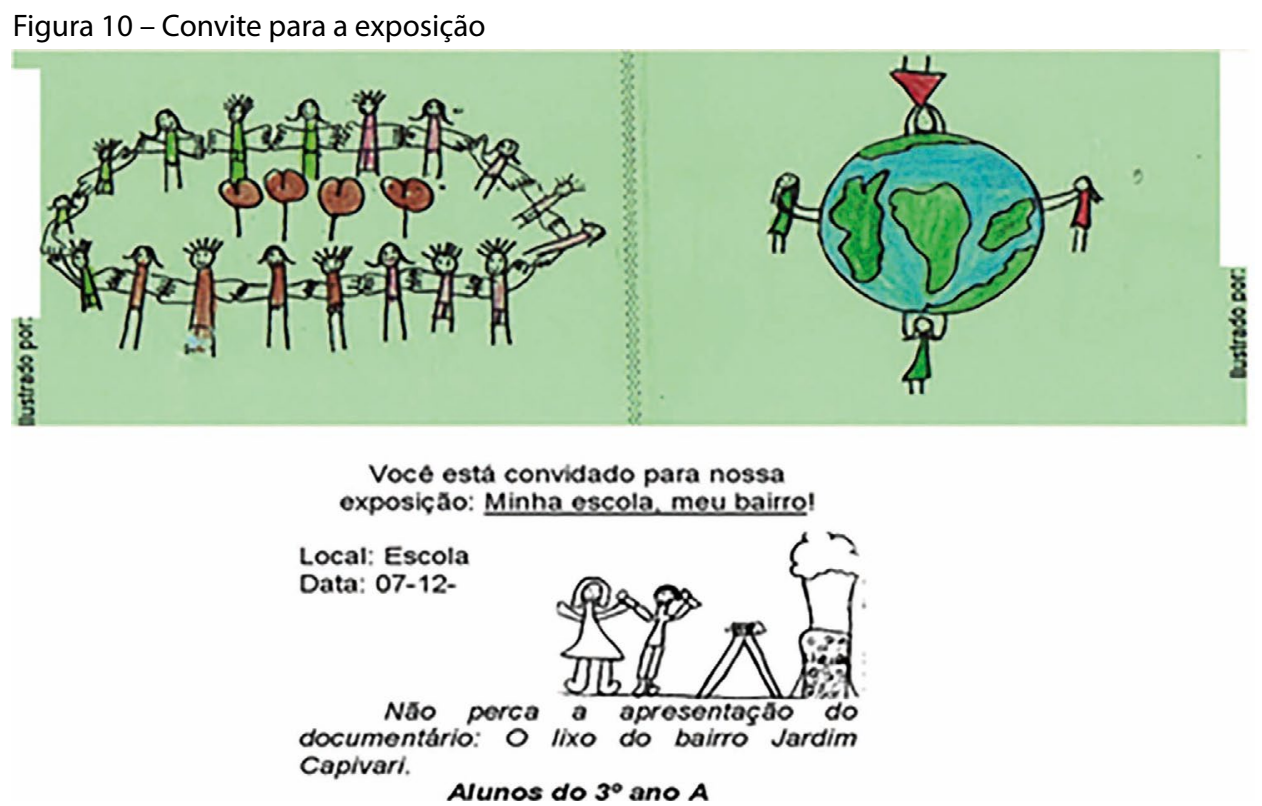

Fonte: elaboração das autoras. 


\section{Discussão}

A descrição detalhada, mesmo que breve, das atividades realizadas no contexto do projeto tem por objetivo oferecer ao leitor um panorama da variedade de ações, atividades, interações e conhecimentos mobilizados durante o semestre por professores e alunos. Praticamente uma vez por mês, a turma do $3^{\circ}$ ano saiu da escola a pé ou de ônibus para percorrer o bairro, recolher o lixo, conhecer a cidade e seus movimentos e visitar o Instituto Estre, que realiza um trabalho de educação ambiental em um município próximo. As saídas envolveram um intenso trabalho: foi preciso estudar, planejar e preparar os materiais para empreender depois o reconhecimento e registro dos aspectos centrais de cada questão abordada.

Os recursos utilizados foram variados: desenho, escrita, fotografia, pintura, escultura, filmagem, técnicas de conservação, leitura de livros e revistas, pesquisa na internet, entrevistas, assistência a palestras e filmes, aulas expositivas, diálogos e rodas de conversa. $\mathrm{O}$ uso de cada um desses recursos demandou o aprofundamento e o aprimoramento dos conhecimentos relacionados a eles.

Todas as atividades citadas foram desdobradas em questões cujas respostas nortearam as inúmeras ações a que deram lugar. Tomemos como exemplo a Saída de campo (2) e a confecção das obras de arte com o lixo recolhido. O planejamento da saída envolveu a confecção da lista dos materiais necessários: máscaras e luvas para proteger os participantes da contaminação, da sujeira e de elementos que pudessem afetar a saúde; sacos de lixo para recolher o material; cadernos e lápis para descrever os problemas ambientais encontrados; a elaboração de um roteiro de perguntas que deveriam ser respondidas a partir da observação dos locais visitados e câmera para efetuar o registro fotográfico. Ao retornar da saída, outras atividades se sucederam: classificação do lixo; separação dos materiais; higienização e acondicionamento em caixas e sacos devidamente etiquetados; estudo das técnicas de conservação e do uso artístico dos materiais recicláveis; discussão das relações entre produção de bens, consumo e produção de lixo entre outras. Ainda, durante a elaboração das obras foram discutidas as técnicas de representação, uso da cor, textura, composição, manejo do espaço, e foram confeccionadas também as legendas para as obras, especificando título, autor e ano.

O conjunto e a variedade de atividades propostas colaboraram para estabelecer na sala um ritmo dinâmico e intenso em muitos momentos. Algumas crianças avançaram no processo de alfabetização, que ainda estava em curso, apesar de já terem passado por três séries do ensino fundamental. Todos os alunos se beneficiaram ao participar do projeto, aprender a se organizar e a se responsabilizar por diferentes tarefas e, também, a discutir nas rodas de conversa e aulas as múltiplas 
facetas do problema do lixo. Questões históricas, biológicas, geográficas, físicas e químicas relacionadas à produção social de materiais que acabam no lixo, incluindo-se o problema do descarte consciente e da responsabilidade com o meio ambiente, foram aspectos aprofundados durante a realização do projeto, com o objetivo de comunicar, ao público que assistiria à exposição, os conceitos mais relevantes sobre esse problema. Essas reflexões foram elaboradas em textos escritos pelos alunos.

\section{Considerações finais}

A partir da formulação e da implementação das propostas de intervenção nas salas de aula, emerge - do sucesso alcançado na condução das atividades - a ideia de que o trabalho integrado de disciplinas, cujos conhecimentos se articulem em torno de propostas temáticas que possam ser desenvolvidas em parceria por professores com diferentes formações e especialidades, dinamiza, apoia e promove o trabalho escolar, ampliando o significado cultural das atividades e as suas possibilidades de gerar, nos alunos, interesse e envolvimento pessoal. Nesse sentido, a disciplina de Artes confirma seu potencial como elemento integrador e motivador. Constata-se, ainda, que ela ajuda a derrubar todo tipo de barreiras à aprendizagem, ao lançar mão de técnicas e métodos que requerem habilidades e conhecimentos diversos e ao requisitar o trabalho coletivo e cooperativo. A disciplina de Artes também propicia o contato com temas, técnicas e tecnologias cada vez mais difundidas, e pode ajudar a descortinar para os alunos novas áreas de interesse. O exercício de criação artística admite, entre os seus componentes, a liberdade para utilizar diferentes meios e recursos expressivos. Não há soluções ou respostas únicas e cada criação pode ser valorizada na sua singularidade.

As competências básicas de leitura, escrita, ciências e matemática envolvidas nessas atividades se tornam, assim, instrumentos que os alunos se empenham em dominar para atingir os objetivos por eles previstos. Esse fato remete à democratização do conhecimento e das ferramentas que permitem a sua apropriação. Durante o desenvolvimento do projeto aqui relatado, destacamos o protagonismo assumido pelos alunos. Auxiliados pelas professoras, eles adquiriram as ferramentas necessárias para elaborar aspectos da história pessoal, familiar, do bairro e da comunidade. Essas elaborações remeteram os alunos à herança cultural, gerando interesse em conhecer e valorizar as próprias origens. Podemos considerar que esses são os primeiros passos de uma longa caminhada, que pode conduzir a conhecer e valorizar o patrimônio cultural coletivo.

Para finalizar, resta-nos, agora, retomar uma das perguntas inicialmente formuladas: se o trabalho com projetos oferece tantas vantagens, por que ele é pouco 
usado e, mais do que isso, por que as políticas de estados e municípios se inclinam de forma crescente em favor dos sistemas apostilados, compostos, na maioria das vezes, por sequências fixas de atividades obrigatórias?

A análise da proposta revelou que o trabalho com projetos é uma modalidade com imenso potencial para propiciar a criatividade, a curiosidade e o conhecimento integrado à vida social e à cultura. Contudo, os modos de organização da escola, a predominância de atividades diretamente vinculadas com as avaliações obrigatórias, a formação disciplinar e o escasso tempo disponível para que os professores articulem e planejem propostas conjuntas, entre outros fatores, conspiram contra a realização desse tipo de atividade e impedem que a escola proponha estratégias mais significativas e plenas de sentido para os seus alunos.

Concluímos com a reflexão sobre a necessidade de se repensar as tarefas escolares propostas aos alunos: para além de garantir os pontos necessários para atingir às médias para aprovação nas avaliações, elas poderão ou não ajudá-los a compreender a complexa realidade em que vivem e a assumir o protagonismo que deles se espera.

\section{Art, culture and school knowledge: integration is possible!}

\section{Abstract}

A small university based research team and two school teachers at a public primary school in a city of the state of São Paulo created, in the context of a research project funded by a state financing agency, a work proposal that integrates different areas of knowledge, including Arts while working with projects on shared topics. The proposal was based on the idea that the appropriation of culture depends on a set of actions and knowledge that can be mobilized to understand reality and to act upon it. Starting from de initial selection of a thematic axis, the teachers planned different activities that promoted the student's engagement and involved a variety of knowledge and research actions, teaching and learning. The present study elaborates on the implications of working with projects that propose the integration of disciplines and areas of knowledge in the classroom and on their potential to change the conceptions and practices that tend to fragmentation and to amplify and enrich the culture of every participant.

Keywords: Culture. Projects. Interdisciplinary. School. Teaching-learning.

\section{Nota}

1 Fundação de Amparo à Pesquisa do Estado de São Paulo. 2010-2013. 


\section{Referências}

ARSLAN, Luciana Mourão; IAVELBERG, Rosa. Ensino de arte. São Paulo: Thomson, 2006.

BARBOSA, Ana Mae. Educação e desenvolvimento cultural e artístico. Educação e Realidade, Porto Alegre, v. 2, n. 2, p. 9-17, jul./dez. 1995.

BOSI, Alfredo. Reflexões sobre a arte. São Paulo: Ática, 1986.

BOURDIEU, Pierre. A economia das trocas simbólicas. São Paulo: Perspectiva, 2004.

A escola conservadora: as desigualdades frente à escola e à cultura. In: NOGUEIRA, M. A.; CATANI, A. (Org.). Pierre Bourdieu: escritos de educação. Petrópolis: Vozes, 1998. p. 39-64.

CORRÊA e CASTRO, Marcelo Macedo; AMORIM, Rejane Maria de Almeida. A formação inicial e a continuada: diferenças conceituais que legitimam um espaço de formação permanente da vida. Cadernos Cedes, Campinas, v. 35, n. 95, p. 37-56, jan./abr. 2015.

FREIRE, Paulo. A importância do ato de ler em três artigos que se completam. São Paulo: Cortez, 1995.

GONÇALVES, Dayane. Das políticas às práticas pedagógicas. Relatório de Pesquisa. Campinas: Fapesp, 2010.

. Das políticas às práticas pedagógicas. Relatório de pesquisa. Campinas: Fapesp, 2011.

HERNANDEZ, Fernando; VENTURA, Montserrat. A organização do currículo por projetos de trabalho; o conhecimento é um caleidoscópio. Porto Alegre: Artes Médicas, 1998.

KLEIMAN, Angela. Modelos de letramento e as práticas de alfabetização na escola. In: (Org.). Os significados do letramento. Campinas: Mercado de Letras, 1995. p. 15-61.

LAPLANE, A. L. F. Das políticas às práticas pedagógicas. Relatório de pesquisa. Campinas: Fapesp, 2013.

MAGALHÃES, Lígia Karam Corrêa de; AZEVEDO, Leny Cristina Soares Souza. Formação continuada e suas implicações: entre a lei e o trabalho docente. Cadernos Cedes, Campinas, v. 35, n. 95 , p. 15-36, jan./abr. 2015.

MOTA, Kátia Maria Santos. A linguagem da vida, a linguagem da escola: inclusão ou exclusão? Revista da FAEEBA, Salvador, v. 11, n. 17, p. 13-26, jan./jun. 2002

NOGUEIRA, Maria Alice; CATANI, Afrânio. Pierre Bourdieu: escritos de educação. Petrópolis: Vozes, 1998.

PILLAR, Analice Dutra. Regimes de visibilidade nos desenhos animados da televisão. Porto Alegre: Fapergs/Ufrgs, 2004.

PORTELA, Tatiana Brochado. Das politicas às práticas pedagógicas. Relatório de pesquisa. Campinas: Fapesp, 2010.

. Das políticas às práticas pedagógicas. Relatório de pesquisa. Campinas: Fapesp, 2011.

ROJO, Roxane (Org.). Alfabetização e letramento: perspectivas linguísticas. Campinas: Mercado de Letras, 1998. 
SOARES, Magda. Letramento e alfabetização: as muitas facetas. Revista Brasileira de Educação, Rio de Janeiro, n. 25, p. 5-17, 2004.

STREET, Brian. Perspectivas culturais sobre o letramento. Filologia e Linguística Portuguesa 8. São Paulo: Edusp, 2006.

What's "new" in New Literacy Studies? Critical approaches to literacy in theory and practice. Current Issues in Comparative Education, Columbia: Teachers College, Columbia University, v. 5, n. 2, p. 77-91, 2003.

TARDIF, Maurice. A profissionalização do ensino passados trinta anos: dois passos para a frente, três para trás. Educação e Sociedade, Campinas, v. 34, n. 123, p. 551-572, abr./jun. 2013.

VIGOTSKY, Lev Seminovich. A formação social da mente. São Paulo: Martins Fontes, 1991. 